\title{
Introducing Web 2.0: wikis for health librarians
}

\author{
Eugene Barsky and Dean Giustini
}

\begin{abstract}
This paper is an introduction to wikis for health librarians. While using wikis in health is now well established, their gradual rise is similar to other Web 2.0 tools such as blogs and RSS feeds. The same principles of collaboration, knowledge-sharing, and socialization apply to wikis. Easy-to-use, interactive, and built on open platforms (though not all are free), wikis offer a number of marketing and teaching opportunities for health librarians. Ironically, owing to the prominence of Wikipedia, which paved the way for the broader acceptance of Web 2.0 technologies, wikis are moving beyond the collaborative writing of encyclopedia entries. Wikis are now used for all kinds of projects, from managing internal library content to revising important reference sources such as the International Classification of Diseases (ICD). That said, some physicians and librarians express grave concerns about using wikis to create reference works-particularly, how questionable authority and editorial controls may result in medical errors. We argue that wikis were not necessarily meant to replace trusted print and digital information. When used responsibly as part of an overall content management plan, wikis can enhance our traditional collections and services. The authors predict that wikis will continue their rise in medicine through 2008, which will lead to other creative uses and applications in health libraries.
\end{abstract}

\section{Introduction}

This is another article in a Journal of the Canadian Health Libraries Association series about Web 2.0 technologies in health [1-4]. Several medical journal articles [5-8] have looked at social software from various points of view since the series began. Taken together, these articles offer considerable scope for those health librarians interested in deepening their understanding of Web 2.0 and its impact in health care.

An important theme in much of the health library literature is that Web 2.0 represents a transition of some kind, as well as a new way of working together. Some of the recurring aspects of this discourse are the possible uses of wikis in filesharing, editing, content aggregation, and customization among disparate users. In a recently published article, Boulos and Wheeler emphasize the potential of Web 2.0 to create new knowledge in a distributed fashion: "[these] technologies represent a quite revolutionary way of managing and repurposing/remixing online information and knowledge repositories, including clinical and research information" [5]. Moreover, Connor warns, "Medical librarians who lack understanding of the Web 2.0 ecosystem risk marginalization within present user communities, and may miss opportunities to work collaboratively with colleagues and clientele" [6].

As with blogs and RSS feeds, health librarians should examine the potential of wikis as they represent an important publishing trend. McLean et al. summarize this trend by stating "social technologies are characterised by constant de- velopment and evolution as a result of user interaction. Those who use these services assist in their development and are part of the 'collective intelligence' which is harnessed to make the services better and more responsive" [8]. By developing expertise in Web 2.0 tools, health librarians can assert new social, technology, and teaching roles for themselves within their organizations.

\section{The wiki concept}

The idea of a wiki ("wiki" is a Hawaiian term for quick or super fast) was first coined by Ward Cunningham in 1994. Cunningham favoured the idea of sharing information without the kinds of encumbrances that normally inhibit peer-topeer conversation, collaboration, and knowledge-creation. Taking this idea one step further, participants can use wikis to share and exchange ideas without the need for elaborate coding languages such as hypertext markup (HTML). Another important feature is Web-based editing where participants create pages and, as documents evolve, changes are tracked as "histories" in an underlying database.

According to Wikipedia, "a wiki is a type of Web site that allows the visitors themselves to easily add, remove, and otherwise edit and change some available content, sometimes without the need for registration. The ease of interaction and operation makes a wiki an effective tool for collaborative authoring." But the social, open nature of wikis is what makes them revolutionary, controversial, and occasionally problematic. While useful for many projects, wikis

E. Barsky. Irving K. Barber Learning Centre, 1961 East Mall, Vancouver, BC V6T 1Z1, Canada. E-mail: eugene.barsky@ubc.ca; Blog: http://weblogs.elearning.ubc.ca/physio/.

D. Giustini. Diamond Health Care Centre and Vancouver Hospital, Vancouver, BC V5Z 1M9, Canada. E-mail: dean.giustini@ubc.ca; Blogs: http://weblogs.elearning.ubc.ca/googlescholar/ and http://blog.openmedicine.ca/. 
may not always be well suited to, say, building drug, medical procedure, practice guideline, or complementary and alternative therapy (CAM) texts. In fact, any information source where accuracy and authority must be of the highest standards may be ill suited to the wiki concept.

That said, there are many wiki applications in libraries worth reviewing. Librarians use wikis to build repositories, manage intranets, and create dynamic content for Web sites, pathfinders, and other library tools. Experimentation includes a range of uses, including sharing information and expertise with colleagues at reference desks and user communities "as events happen" (similar to informing friends using Facebook, for example) [4].

The blurring of the original concept of a wiki has led to some confusion as to what defines it (some Web sites are a combination of a blog and wiki, and are called "blikis"). According to Lamb [9], wikis have five characteristics that separate them from other social computing activities:

(1) Uniqueness - Wikis provide an opportunity to share original content in niche areas that might not be found elsewhere. Rather than duplicate Web content, wikis can link to existing information beyond the scope of a project.

(2) Collaborative - Wikis are designed to be free, open spaces for sharing. Rather than focus on a single author's contribution, wikis concentrate on the synergy that comes from multiple contributers.

(3) Open - Anyone can add anything to a wiki at any time. Although many wikis, particularly in health, require registration or guest access for outsiders, most allow anyone to join in the journey.

(4) Simple - Anybody can learn to create and edit pages using the Web-based forms. In most cases, the tools are similar to a word processor.

(5) Evolving - Wikis are in a constant state of change. They are dynamic entities and reflect the evolution of a particular subject.

With that, let's examine some of the wiki experimentation taking place in medicine.

\section{Wikis in medicine}

There are numerous applications of wikis in medicine. We would like to mention three expert-moderated wikis in health sciences:

(i) Ask Dr. Wiki (http://www.askdrwiki.com) is "a nonprofit educational Web site made by physicians for physicians, medical students, and health care providers. Its purpose is to serve as an online repository of medical information that can be accessed by anyone." This is a wiki with a detailed editorial policy (http://tinyurl.com/3do9rq) where authors must be approved as physicians before editing the wiki. For more information, see the AskDrWiki entry in Wikipedia (http://en.wikipedia.org/wiki/Ask_Dr_Wiki).

(ii) Ganfyd (http://www.ganfyd.org/) is a "free medical knowledge base that anyone can read and any registered medical practitioner may edit. Ganfyd is a collaborative medical reference by medical professionals and invited non-medical experts. The site is based around the wiki format, enabling true sharing of knowledge." This wiki has restricted editorial policies that allow only registered medical practitioners to add and edit content.

(iii) PubDrug (http://www.pubdrug.org/) is an "open-access, peer-reviewed, copyright- and royalty-free drug information database intended for the use of pharmacists and other health professionals. PubDrug is being developed as a wiki, making it possible to harness expertise from anyone connected to Internet. However, PubDrug also provides editorial guidelines and fact-checking procedures to keep its drug information as error-free as possible." As with the above wikis, contributors must be approved by administrators, which include a pharmacy librarian.

There has been a sharp increase in the use of wikis in medicine in 2007. To see the range of the more than 50 medical wikis in development, see David Rothman's comprehensive list of health-related wikis on his blog (http://davidrothman.net/list-of-medical-wikis/).

\section{Wikis in libraries}

Wikis are often used as starting points for users doing research as well as a digital "town square" or shared workspace. Their potential uses include brainstorming, project and knowledge management, and a collaborative space for document creation, to name a few. Other possible applications are the following:

(i) Subject guides - St. Joseph County Public Library, for example, uses wikis to create, update, and maintain their subject guides (http://www.libraryforlife.org/ subjectguides/index.php/Main_Page).

(ii) Project planning - A group of University of British Columbia (UBC) librarians placed materials on a free Web-based wiki to teach Web 2.0 tools (http://tots.pbwiki.com/).

(iii) Policy manuals - The Library Success: A Best Practices Wiki (http://www.libsuccess.org) was created to share the successful implementation of new ideas and information for all types of librarians. Coordinated by Meredith Farkas, it has become a place to share policies, success stories, and case studies.

(iv) Training resources - At the 2007 Canadian Health Libraries Association / Association des bibliothèques de la santé du Canada (CHLA / ABSC) conference, Giustini and Barsky used the UBC Health Library wiki as a manual and starting point for training (http://tinyurl.com/yp9hsc).

\section{Wikis as knowledge base}

In September 2006, a health library wiki was created to support a health libraries course at the UBC School of Library, Archival and Information Studies (SLAIS). The UBC Health Library wiki was established using MediaWiki, a server-based product and the most recognizable wiki tools. MediaWiki, which is used by Wikipedia, provides excellent functionality and scalability. However, it requires server support, which we obtained through the UBC Faculty of Arts. To use interactive, collaborative social software, the SLAIS instructors (both of whom are librarians) envisioned the wiki as a place to share 
information in context and to build a knowledge base for health librarians. And when appropriate to do so, each wiki entry included a section entitled the "Canadian context".

Health librarians from across Canada (including CHLA / ABSC members) were encouraged to contribute to the wiki. We currently have 150 articles, 1542 total pages, and 100 registered users on the wiki. It is currently being used for a variety of purposes including evaluating databases and discussing information retrieval, library technologies, and hospital accreditation. Other hot topics include evidence-based medicine, systematic reviews, qualitative research, and teaching. While Canadian perspectives are much appreciated, we welcome American, British, and Australian colleagues to lend an international perspective to the content.

To aid in navigation and editing, a team of health librarians and Master of Library and Information Studies (MLIS) students wrote an editing policy and user's guide, which included guidelines about how to write articles. All wikipedians were asked to be familiar with the help section and to read the guidelines thoroughly. Part of wiki-ing is reading well, so we asked contributors to read entries critically. Entries that do not come with "sources consulted" (links to books or Web sites in the references) were considered to be invalid and removed. As of this writing, we have had more than 260000 page views on the wiki, and there is discussion of moving the UBC Health Library wiki to the CHLA / ABSC servers for expansion and to take it to the next level as a shared knowledge base for health librarians.

\section{Selecting your own wiki}

Selecting a wiki can be a time-consuming process. First, wiki software must be selected based on available hosting options. Do you want a Web-based or server-based wiki? Available resources, computer support, and expertise in your organization are important considerations. To evaluate the various wikis available, sign up for a few free accounts and experiment. Wikis hosted by various Web sites can be used in minutes, whereas server installation for a locally hosted wiki may take time and technical expertise to implement.

Two of the best-known Web-hosted wikis are

(i) Pbwiki (http://pbwiki.com) - We use a free version of Pbwiki for our internal library projects in the UBC Library: planning, teaching, and communications. One example of this use is a free wiki for teaching Web 2.0 (http://tots.pbwiki.com/).

(ii) Wetpaint (http://www.wetpaint.com/) - One important example of Wetpaint wikis in health libraries is the EBM Librarian wiki (http://ebmlibrarian.wetpaint.com), the purpose of which is "to develop a community of librarians who are involved in teaching and supporting the practice of Evidence Based Medicine or Evidence Based Practice".

There are a number of open-source server-based options available to health librarians. As mentioned, Mediawiki (www.mediawiki.org) is the software of choice for many wiki projects, including the UBC Health Library wiki (http://hlwiki.slais.ubc.ca).

\section{Challenges}

Some of the challenges in using wikis are

(1) Lack of authority and editorial controls - Many health librarians are concerned about the use of wikis to create sources of information and reference works, especially where editorial controls are minimal. High editorial standards in medicine have led to the idea of expertmoderated wikis.

(2) Wikispam - Wikis are vulnerable to link spam. Spambots dump unwanted data into wikis and are a growing threat to wiki projects. Cleaning up wikis can be time consuming and can take away from building your wiki content.

(3) Content - Controversial topics can result in disagreements. If content is not well documented, users may debate, add, or correct information as needed. Some wikis require registration, and many private wikis require authentication every time an edit or change is made. In the near future, Wikipedia plans to test a color-coding tool to mark questionable content on articles. The color-coding scheme will give Wikipedians a sense of how many times sections of articles have been revised as a means to see what sections are the most disputed and controversial; by extension, entries virtually unchanged over longer periods of time will indicate consensus of the crowd [10].

(4) Minimal use - Implementing a wiki is a challenge when it is not well used. Training may be required to teach users how to learn the basics of wiki navigation and editing. Some wikis have found that they need to offer incentives for users to contribute content.

(5) Web 2.0 resistance - The notion of collaboration and group authoring may be at odds with an organization's work culture. Some administrators see wikis as untenable or even disruptive. Health librarians may be required to advocate for Web 2.0 tools in their organizations, even at top administrative levels.

(6) Vandalism - The openness of most wikis means that vandalism can result. Undoing damage is annoying and time consuming.

\section{Conclusion}

Wikis bring a dynamic, user-centered element to online pathfinders, Web sites, and handouts. They can be used in conjunction with other social software to deliver innovative aspects to library services. Where health librarians need to coordinate larger projects, especially where "group brainstorming" and wisdom of the collective is important, wikis offer options beyond the ubiquitous software tools on our desktops. Many libraries have begun to experiment with wiki technologies to build knowledge repositories, manage intranet resources, and create content for continuing education.

The future use of wikis will see the integration of other Web 2.0 tools, such as blogs, podcasts, and RSS feeds. We hope that the replacement of expensive print and digital sources of information (e.g., UpToDate), using wikis (or other open-source publishing platforms) is the next wave in use of the technology. Evidence-based content creation holds particular promise for health librarians who want to collabo- 
rate with physicians and other health professionals in innovative publishing projects.

\section{References}

1. Barsky E, Cho A. Introducing Web 2.0: social search for health librarians. J Can Health Libr Assoc. 2007;28(2):58-61.

2. Barsky E. Introducing Web 2.0: RSS trends for health librarians J Can Health Libr Assoc. 2006 Winter;27(1):7-8.

3. Barsky E. Introducing Web 2.0: weblogs and podcasting for health librarians. J Can Health Libr Assoc. 2006 Spring;27(2):33-4.

4. Barsky E, Purdon M. Introducing Web 2.0: social networking and social bookmarking for health librarians. J Can Health Libr Assoc. 2006 Summer;27(3):65-7.
-5. Boulos MN, Wheeler S. The emerging Web 2.0 social software: an enabling suite of sociable technologies in health and health care education. Health Info Libr J. 2007 Mar;24(1):2-23.

-6. Connor E. Medical Librarian 2.0. Med Ref Serv Q. 2007 Spring;26(1):1-15.

7. Giustini D. How Web 2.0 is changing medicine. BMJ. 2006 Dec 23;333(7582):1283-4.

8. McLean R, Richards BH, Wardman JI. The effect of Web 2.0 on the future of medical practice and education: Darwikinian evolution or folksonomic revolution? Med J Aust. 2007 Aug 6;187(3):174-7.

9. Lamb B. Wide open spaces: wikis ready or not. Educause Review. 2004;39(5):36-48.

10. Open Medicine Blog. Judging the Reliability of Wikipedia Through Colour. [Accessed 2007 Aug 8.] Available at http://blog.openmedicine.ca/node/71. 